\title{
Review: self management education improves outcomes in children and adolescents with asthma
}

\author{
Wolf FM, Guevara JP, Grum CM, Clark NM, Cates CJ.Educational interventions for asthma in children. Cochrane Database \\ Syst Rev 2003;(1):CD000326 (latest version Aug 1, 2002).

\section{QUESTION: In children and adolescents with asthma, are self management education interventions effective at improving lung function and decreasing morbidity and healthcare use?}

\section{Data sources}

Studies were identified by searching the Cochrane Airways Group's and Cochrane Schizophrenia Group's Special Registers of Controlled Trials (the Schizophrenia register comprises references from PsycLIT), and reviewing bibliographies of relevant articles.

\section{Study selection}

Studies were selected if they were randomised controlled trials (RCTs) or controlled clinical trials (CCTs) comparing an educational intervention designed to teach $\geq 1$ self management strategy related to prevention, attack management, or social skills with usual care; measured objective outcomes; and patients were children or adolescents, $2-18$ years of age.

\section{Data extraction}

Data were extracted on sample size, demographic characteristics of the patients, details of the intervention,

this abstract appears in

Evidence Based

Nursing.

al interventions $v$ usual care in youth children and adolescent Self management educational in
with asthma at $6-12$ months *

\begin{tabular}{lccl} 
Outcomes & $\begin{array}{l}\text { Number of } \\
\text { RCTs }\end{array}$ & $\begin{array}{l}\text { Number of } \\
\text { patients }\end{array}$ & $\begin{array}{l}\text { Standardised mean } \\
\text { difference }(95 \% \text { Cl) }\end{array}$ \\
\hline Lung function & 2 & 106 & $0.59(0.20$ to 0.99$)$ \\
\hline Self efficacy scale & 5 & 256 & $0.33(0.08$ to 0.58$)$ \\
\hline Days of school absences & 12 & 1388 & $-0.13(-0.23$ to -0.02$)$ \\
\hline $\begin{array}{l}\text { Number of visits to the } \\
\text { emergency department }\end{array}$ & 9 & 932 & $-0.23(-0.36$ to -0.09$)$ \\
\hline Days of restricted activity & 4 & 290 & $-0.20(-0.43$ to 0.04$) \dagger$ \\
\hline Nights disturbed by asthma & 2 & 139 & $-0.11(-0.45$ to 0.23$) \dagger$ \\
\hline Asthma severity scale & 3 & 170 & $-0.05(-0.35$ to 0.26$) \dagger$ \\
\hline Number of exacerbations & 3 & 249 & $-0.12(-0.37$ to 0.13$) \dagger$ \\
\hline $\begin{array}{l}\text { Number of visits to the general } \\
\text { practitioner }\end{array}$ & 6 & 619 & $-0.15(-0.31$ to 0.01$) \dagger$ \\
\hline
\end{tabular}

${ }^{*} \mathrm{RCTs}=$ randomised controlled trials. $\mathrm{Cl}$ defined in glossary.

${ }^{*} \mathrm{RCTS}=$ randomised contro
†Not statistically significant.

study setting and quality, and outcomes. Outcomes included measures of lung function, morbidity and functional status, self perception, and healthcare use.

\section{Main results}

26 RCTs and 6 CCTs (altogether 3706 youth) met the selection criteria. The self management educational programmes evaluated in the trials differed by type of educational session (group sessions, individual session, or both), intensity (single session, 2 sessions, or $\geq 3$ sessions), self management strategy (peak flow or symptom based strategy), and length of the intervention (mean 3.8 mo, range 1-12). Whereas all trials focused on asthma prevention measures (eg, identification and avoidance of asthma triggers) and/or attack management plans (eg, use of an asthma action plan), 13 trials incorporated social skills development into their educational strategy. Meta-analyses of RCTs were done using a fixed effects model. Improvement in lung function and on measures of self efficacy was greater in the self management group than in the usual care group (table). The mean number of days of absence from school and mean number of visits to the emergency department were lower in the self management group than in the usual care group (table). The groups did not differ for days of restricted activity, nights disturbed by asthma, number of exacerbations, asthma severity scores, and visits to the general practitioner (table).

\section{Conclusion}

In children and adolescents with asthma, self management educational interventions are effective for improving lung function, and for decreasing some measures of morbidity and healthcare use.

\section{COMMENTARY}

Asthma education is one of the actions recommended as part of national guidelines for asthma management. ${ }^{1}$ But systematic reviews of the evidence supporting this recommendation have been lacking until now. The reviews by Powell and Gibson, and Wolf $e t$ al presented in this issue systematically summarised the literature to determine whether asthma education reduces clinically important morbidity.

Both reviews used extensive literature searches and duplicate and independent data abstraction, and assessed the methodological quality of the individual studies. Important limitations of the studies included in the review by Powell and Gibson reduce the strength of the inferences. Substantial statistical heterogeneity was detected in some of the pooled results, but was reduced or eliminated with the use of standardised mean differences (SMDs). Some of the SMDs were calculated using imputed standard deviations, but the assumed transciption error was not corroborated by the authors of the original trials in question. A random effects model provides a more conservative estimate of the effect size when there is substantial heterogeneity, and may be more appropriate. None of the studies measured all of the outcomes, and a limited number of studies measured certain outcomes such as quality of life. Importantly, a single study in this review showed that less intense education increased unscheduled doctors' visits. ${ }^{2}$

The review on educational interventions for asthma in children by Wolf $e t$ al was more rigorous. They used correspondence with the authors to verify data, subgroup analyses, and comparison of random and fixed effects models. Important limitations of the review included lack of quality of life as an outcome measure, statistical heterogeneity, and a limited number of studies for some important outcomes. The use of SMDs may introduce small sample bias, since the SMD is overestimated with very small sample sizes (usually $<10$ ). ${ }^{3}$ The benefits of self management programmes were manifest at $7-12$ months following education initiation, after initial physiological improvements. Behaviour modification is delayed, and patients must first learn methods to control their asthma and prevent exacerbations. 


\section{Review: regular medical review is equivalent to written self management plans for optimising asthma control in adults}

Powell H, Gibson PG. Options for self-management education for adults with asthma. Cochrane Database Syst Rev 2003;(1):CD004107 (latest version 12 Mar 2002).

QUESTIONS: In adult asthmatic patients using inhaled corticosteroids: (i) is regular medical review (RMR) equivalent to written self management plans for optimising asthma control? (ii) are written self management plans based on peak expiratory flow self management (PFSM) equivalent to those based on symptom self monitoring (SSM)?

\section{Data sources}

Studies were identified by searching the Cochrane Airways Group's Special Register of Controlled Trials derived from Medline, EMBASE/Excerpta Medica, and CINAHL and by reviewing bibliographies of relevant articles.

\section{Study selection}

Studies were selected if they were randomised controlled trials (RCTs) of $\geq 2$ self management asthma education interventions in patients with asthma who were $>16$ years of age and which reported relevant health outcomes.

\section{Data extraction}

2 reviewers independently extracted data on sample size, demographic characteristics of the patients, details of the intervention, study setting, study quality, and outcomes. Outcomes included forced expiratory volume in 1 second $\left(\mathrm{FEV}_{1}\right)$, peak expiratory flow, hospital admissions, emergency room visits, unscheduled doctor visits, days lost from work or school, and use of "rescue" medications.

\section{Main results}

15 RCTs (2460 patients) met the selection criteria. Meta-analyses were done using a fixed effects model. Primary comparisons included optimal self management with RMR (6 RCTs) comparing 2 interventions which optimised asthma control using dose adjustment of inhaled corticosteroids either by active RMR or an individualised written self management plan where dose adjustment was based on PFSM or SSM. Meta-analysis of 3 RCTs $(n=707)$ showed that the groups did not differ in their $\mathrm{FEV}_{1}$ or peak expiratory volume (table). The groups also did not differ for hospital admissions for asthma (4 RCTs), emergency room visits (1 RCT), unscheduled doctor visits (3 RCTs), days off work or school (2 RCTs), nocturnal asthma (3 RCTs), and disrupted days (1 RCT). The other primary comparison was PFSM with SSM (6 RCTs). Meta-analysis showed that the groups did not differ for hospital admissions (4 RCTs, $\mathrm{n}=412$ ) and emergency room visits (5 RCTs, $\mathrm{n}=512$ ) (table), and unscheduled doctor visits, days lost from work, and oral corticosteroid use.

\section{Conclusions}

In adult asthmatic patients using inhaled corticosteroids, (i) regular medical review is equivalent to written self management plans, and (ii) self management plans based on peak expiratory flow are equivalent to those based on symptom self monitoring.

Source of funding:
Cooperative Research
Centre for Asthma
Australia.
For correspondence:
DrP Gibson, John
Hunter Hospital, NSW,
Australia.
mdpgg@
mail.newcastle.edu.au
A modified version of
this abstract appears in
Evidence Based
Nursing.

Peak expiratory flow self management (PFSM) v regular medical review (RMR) or symptoms self monitoring (SSM) at $\geq 6$ month*

\begin{tabular}{|c|c|c|c|c|c|}
\hline Outcomes & $\begin{array}{l}\text { Number } \\
\text { of RCTs }\end{array}$ & Comparison & \multicolumn{3}{|c|}{ Standardised mean difference $(95 \% \mathrm{Cl})$} \\
\hline $\begin{array}{l}\text { Mean forced } \\
\text { expiratory volume } \\
\text { in } 1 \text { second }(\mathrm{ml})\end{array}$ & 3 & PFSM $v$ RMR & \multicolumn{3}{|c|}{$0.01(-0.14$ to 0.15$) \dagger$} \\
\hline $\begin{array}{l}\text { Mean peak } \\
\text { expiratory flow } \\
\text { (ml) }\end{array}$ & 3 & PFSM $v$ RMR & \multicolumn{3}{|c|}{$0.06(-0.09$ to 0.21$) \dagger$} \\
\hline & & & $\begin{array}{l}\text { Weighted } \\
\text { event rates }\end{array}$ & RRI (Cl) & NNH \\
\hline \multirow[t]{2}{*}{$\begin{array}{l}\text { Hospital admission } \\
\text { (patients) }\end{array}$} & 4 & PFSM $v$ SSM & $4 \%$ v $3 \%$ & $17 \%(-56$ to 212$)$ & $\begin{array}{l}\text { Not } \\
\text { significant }\end{array}$ \\
\hline & & & & RRR & NNT \\
\hline $\begin{array}{l}\text { Emergency room } \\
\text { visits (patients) }\end{array}$ & 5 & PFSM $v$ SSM & $15 \%$ v $16 \%$ & $9 \%(-35$ to 39$)$ & $\begin{array}{l}\text { Not } \\
\text { significant }\end{array}$ \\
\hline
\end{tabular}

${ }^{*} \mathrm{RCTs}=$ randomised controlled trials. Abbreviations defined in glossary; RRI, RRR, NNH, NNT and Cl calculated from data in article.

†Not statistically significant.

\section{COMMENTARY - continued from previous page}

Despite these caveats, self management programmes seem to be useful for managing asthma optimally. According to Powell and Gibson, just providing one-and intensively-seems to be the key, rather than the type of programme. Self management may provide patients with a sense of control over their asthma, reducing dependence on the healthcare professional and system. In particular, the use of a peak flow meter reduces school absenteeism, nocturnal symptoms, healthcare use, and admissions to hospital compared with symptom based strategies in children but not adults. Perhaps children are especially poor at estimating their bronchoconstriction until they learn to associate what they measure with their symptoms. The efficacy of self management programmes on quality of life remains uncertain.

Tasnim Sinuff, MD FRCPC McMaster University, Hamilton, Ontario, Canada

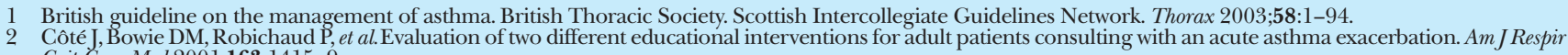
Crit Care Med 2001;163:1415-9.
Rosenthal R. Parametric measures of effect size. In: Cooper H, Hedges LV, editors. The handbook of research synthesis. New York: Russell Sage Foundation, 1994. 